\title{
ENIGMAS DA GESTÃO DE PESSOAS: UM ESTUDO COM GESTORES
}

Felipe Gouvêa Pena ${ }^{1}$

Letícia Rocha Guimarães ${ }^{2}$

Milene Cristine ${ }^{3}$

\footnotetext{
${ }^{1}$ Centro Universitário de Belo Horizonte

${ }^{2}$ Universidade Federal de Minas Gerais

${ }^{3}$ Universidade Federal de Ouro Preto
} 


\section{ENIGMAS DA GESTÃO DE PESSOAS: UM ESTUDO COM GESTORES}

\section{Resumo:}

Este artigo se propõe a compreender como gerentes de pequenos negócios lidam com dilemas relacionados à gestão de pessoas na cidade de Belo Horizonte, a partir dos inescapáveis enigmas da gestão, mencionados nos estudos de Mintzberg (2010), especificamente o "enigma de pessoas". Em uma abordagem qualitativa de caráter exploratório e descritivo, foram investigadas 45 empresas. O processo de coleta de dados foi pensado a partir da aplicação de um questionário, sendo os dados categorizados e observados à luz da análise de conteúdo. Os resultados demonstram interessantes táticas e estratégias de gestão, apresentando dilemas e formas de atuação específicas dos gestores de pequenos negócios.

Palavras-chave: Gerentes. Enigmas. Gestão de Pessoas. Pequenas Empresas.

\section{$1 \quad$ Introdução}

As organizações, sejam elas públicas ou privadas, passam por transformações em ritmos acelerados, mundialmente e nacionalmente, que implicam diretamente no ambiente produtivo e nas relações entre empregado e empregador (BAUMAN, 2007). Especialmente na conjuntura contemporânea do Brasil, o ambiente de trabalho desvela-se complexo e multifacetado ao passo que propõe adaptações constantes não apenas aos funcionários, mas também aos gerentes na busca por indivíduos envolvidos e vinculados aos propósitos das organizações (MARIANO; MOSCON, 2018) e, também, no que toca ao acompanhamento de modificações legais no âmbito trabalhista (MARSHESAN, 2017).

Para acompanhar o imediatismo exigido à sustentação de uma organização no mercado, os gerentes, no papel de detentores das principais decisões organizacionais (HILL, 1993), assumem o gerenciamento dos resultados, e concomitantemente, o gerenciamento dos seus empregados, seja das relações interpessoais, seja das atividades desenvolvidas (SILVA; PAULO, 2017; PAIVA et al., 2010).

Neste contexto, políticas e práticas de Gestão de Pessoas no ambiente organizacional podem interferir nas relações estabelecidas entre funcionários e gerentes e o modo com que os gerentes direcionam sua gestão, tende a influenciar como seus funcionários responderão aos desígnios das organizações (DUTRA et al., 2016; MARIANO; MOSCON, 2018).

Quando se trata de compreender uma gestão considerando o porte da organização, vale ressaltar que pequenas empresas não podem ser consideradas miniaturas de grandes organizações, ou seja, o que é aplicável a uma empresa de porte maior, não necessariamente atenderá a uma organização de menor porte. Entretanto, em ambas as situações, a influência do proprietário/gerente é fundamental e determinante no desenvolvimento das atividades empresariais (MESQUITA; MARQUES, 2017).

Neste sentido, o empreendedorismo está diretamente relacionado ao desenvolvimento de um país e à sua prosperidade socioeconômica (DRUCKER, 2008; BRANDSTÄTTER, 2011). Compreender os pequenos negócios e a forma como são gerenciados pelos seus proprietários/gerentes mostra-se relevante aos estudos empíricos e, consequentemente, às 
práticas organizacionais. Há de se ponderar que as pequenas empresas refletem no seu desenvolvimento, o contexto onde estão inseridas quando se trata da gestão, isto é, refletem a influência da personalidade dos seus gerentes, bem como a competência gerencial, experiência no negócio e até mesmo o local em que está estabelecida (REIJONEN, 2008).

De acordo com o Global Entrepreneurship Monitor - GEM - no Brasil, em 2017, a Taxa Total de Empreendedorismo (TTE) foi de 36,4\%, isso significa dizer que de cada 100 brasileiros (as) com idade entre 18 e 64 anos, 36 deles estavam conduzindo atividades empreendedoras (GEM, 2017). Especificamente sobre as Micro e Pequenas Empresas (MPE), foco deste artigo, o Serviço Brasileiro de Apoio às Micro e Pequenas Empresas - SEBRAE (2018) revela que o empreendedorismo neste ramo representa 6,4 milhões dos estabelecimentos, além de $52 \%$ dos empregos com carteira assinada no setor privado.

Brevemente observadas a complexidade e a relevância de se investigar a gestão numa conjuntura de organizações de pequeno porte, assim como os desafios que podem ser enfrentados pelos gestores ao lidar com seus funcionários, este artigo se propõe a compreender como gerentes de pequenos negócios lidam com dilemas relacionados à gestão de pessoas na cidade de Belo Horizonte, a partir dos inescapáveis enigmas da gestão, mencionados nos estudos de Mintzberg (2010), especificamente, o "enigma de pessoas" detalhado no referencial teórico.

\section{Referencial Teórico}

\subsection{Gerência e gerentes}

Desde os estudos de Taylor (1970) a Administração preocupa-se em descrever o papel dos gerentes dentro das organizações. No início do século XX, o profissional que gerenciava uma empresa era o responsável por conceber e promover a execução das tarefas em determinados tempos, de modo a diminuir perdas ou inutilidades no processo de produção.

Fayol (1990) incluiu na descrição de papel do gerente, iniciativa, subordinação dos interesses pessoais aos organizacionais e cuidados com a remuneração dos empregados, no intuito de promover satisfação e manutenção constantes na sua equipe de trabalho.

Continuamente à história da Administração, Weber (1946) apontou o caráter formal da função de um gerente, atribuindo posicionamento "privilegiado" deste profissional na hierarquia organizacional, ao passo que o gerente é tomador de decisões maiores numa empresa.

Simon (1965) complementou esta perspectiva ao mencionar que o gerente deve ser capaz de compreender os dilemas organizacionais, identificar estratégias de ação e, por fim, tomar decisões. Para Drucker (1967) as decisões de um gerente pretendem solucionar causas que trazem problemas para as organizações. Desta forma, ele pode organizar-se a partir de metas que forneçam resultados tangíveis, passíveis de mensuração para apoio ao seu trabalho, enquanto tomador de decisões.

Posteriormente, Mintzberg (1986) discutiu os papéis do gerente, quais sejam: interpessoais, informacionais e decisórios, assim como as habilidades para sua atuação. No Brasil, Motta (1991) aprofundou os estudos destas habilidades, constatando que as mesmas devem evidenciar o contexto organizacional, interpessoal e individual. Tais estudos justificamse pela necessidade de estabelecer junto aos funcionários maior envolvimento, cooperação e dedicação às metas organizacionais (MARIANO; MOSCON, 2018). 
McClelland (1987) trouxe reflexões acerca do poder que um gerente desenvolve nas organizações, percebendo-o como uma das três necessidades humanas; as outras duas estão direcionadas à realização e à afiliação e todas elas podem ser evidenciadas no espaço corporativo de diferentes formas. Likert (1971) apontou que há de se tomar cuidado ao exercer papel de gerente, visto que se o ocupante deste cargo for tipicamente autoritário pode levar os funcionários a buscarem oportunidades de trabalho em outras organizações ou a ineficiências produtivas como forma de retaliação.

Neste mesmo sentido, Hill (1993) salientou a importância e dependência dos gerentes com os diversos atores organizacionais, principalmente seus subordinados, já que os resultados destes influenciam diretamente nos resultados de seus gestores. A autora mencionou em seus estudos que é necessária uma postura flexível do gerente para lidar com sucessos e fracassos de sua equipe (HILL, 1993). Neste mesmo foco, Grum (1995) aludiu que os gerentes devem construir um campo de ação social em sua atuação com vistas ao melhor andamento da organização.

Este processo de construção permanente da ação gerencial não se vislumbra ausente de complexidades, pelo contrário, caracteriza-se principalmente pela pluralidade da posição ocupada, entendida na atualidade pelos desafios vividos por esses profissionais (DUTRA, et al., 2016). Vale destacar ainda que em estudos recentes, reforça-se a ideia de que eles (os gerentes) não correspondem a um grupo homogêneo, isto é, não há possibilidades de delimitar ou julgar determinadas ações de uma função gerencial como corretas em detrimento de outras, considerando que a diversidade de atuação de um gerente conta ainda com a sua própria personalidade, gênero, idade, entre outros (LORENTZ et al., 2014).

Assim, ao analisar aspectos pertinentes à gerência e aos gerentes incorporando-se os desafios enfrentados por estes profissionais em função do cargo exercido, problematizam-se os enigmas que eles vivenciam no tópico subsequente.

\subsection{Enigmas da Gestão}

Em um cenário de acirrada competitividade, em qualquer segmento produtivo, o desempenho dos trabalhadores reflete a atuação do(s) seu(s) gerente(s) e consequentemente, revela o diferencial que uma organização tem para garantir sua sobrevivência e crescimento no mercado. Neste contexto, a busca pela melhoria do desempenho tanto dos trabalhadores, assim como dos próprios gerentes pode ser realizada de divergentes modos, quais sejam: a) de um lado, técnicas mais coercitivas que podem ser questionadas quanto à ética e à eficácia; b) e de outro, estratégias que visem desenvolvimento, envolvendo o trabalhador de modo a exaltar práticas de participação e de colaboração dos mesmos, junto à organização em que prestam seus serviços (MARIANO; MOSCON, 2018).

Bastos et al. (2013) sinalizam que as ações tomadas pelas organizações devem focar em estratégias de gestão visando o cuidado sobre o investimento que é feito no trabalhador, ao passo que deve-se obter consonância entre o serviço prestado e o alcance de resultados almejado pelas empresas. Assim, para o gerente é interessante investir em estratégias de Gestão de Pessoas apropriadas à realidade da sua organização para obtenção de envolvimento, participação e engajamento dos trabalhadores. Considera-se, portanto, que o comportamento do gerente influirá diretamente nos propósitos da empresa (BASTOS; LIRA, 1997; MESQUITA; MARQUES, 2017). 
Para atingir tais propósitos, os gerentes se deparam com enigmas inerentes à gestão e vivenciam um ambiente organizacional de estímulo-resposta ao invés de se aprofundarem em questões que mereçam uma melhor compreensão para soluções mais assertivas (MINTZBERG, 1986). Noutro estudo de Mintzberg (2010) os enigmas da gestão foram detalhados no intuito de dar apoio a gerentes que procuram superar a superficialidade dos paradoxos encontrados no dia a dia. O quadro abaixo descreve estes enigmas:

Quadro 1 - Os enigmas da gestão

\begin{tabular}{|c|l|}
\hline ENIGMAS & \multicolumn{1}{c|}{ CARACTERÍSTICAS } \\
\hline Pensamento & $\begin{array}{l}\text { Problemas: superficialidade na resolução de problemas devido à pressão para finalizar } \\
\text { trabalhos; Falta de tempo para pensar e planejar; Síntese em um mundo decomposto pela } \\
\text { análise. }\end{array}$ \\
\hline Informação & $\begin{array}{l}\text { Dificuldades: Perplexidade da conexão para se manter informado das próprias coisas } \\
\text { gerenciadas; Delegação, visto que tantas informações são pessoais, orais, privilegiadas; } \\
\text { Mensuração da gestão. }\end{array}$ \\
\hline Pessoas & $\begin{array}{l}\text { Desafios: Trazer e manter a ordem no próprio trabalho e no trabalho dos outros; Desordem } \\
\text { controlada, na tentativa de uma imposição da ordem; Estabelecer a confiança na relação } \\
\text { gerente-trabalhador. }\end{array}$ \\
\hline Ação & $\begin{array}{l}\text { Ambiguidades: Agir num mundo complexo; Gerenciar mudança quando é necessário manter } \\
\text { uma continuidade do trabalho. }\end{array}$ \\
\hline Gerais & $\begin{array}{l}\text { Lidar com todos os enigmas expostos e compreender que os mesmos constituem desafios, ao } \\
\text { mesmo tempo. }\end{array}$ \\
\hline
\end{tabular}

Fonte: Adaptado de Mintzberg (2010).

Considerando a complexidade de adentrar em cada enigma, vislumbrou-se o aprofundamento do "enigma de pessoas" no presente estudo. Neste enigma, detalhado na obra de Mintzberg (2010), há uma subdivisão em que se contemplam: a "ordem", o "paradoxo do controle" e o "beco da confiança", na sequência explicitados.

O primeiro, ordem, o autor menciona que as organizações precisam da ordem, mas também da desordem para crescer e o papel do gerente, neste contexto, é de apreender controle em ambas as situações. Sugere-se que o gerente deve ter uma previsibilidade do que pode ser e do que não pode e estar preparado para o que não for ordeiro ou imprevisto (MINTZBERG, 2010). Segundo Grove (1995), o gerente deve deixar o caos reinar e em seguida ter domínio sobre este caos para conseguir levar adiante a empresa.

A segunda subdivisão do enigma de pessoas trata do "paradoxo do controle". Segundo Mintzberg (2010, p. 187) este dilema "descreve o problema de lidar com a desordem do exterior perante a necessidade de ordem no interior". Isso quer dizer que os gerentes têm de trabalhar em condições de uma desordem controlada tanto com as pessoas como com as atividades exercidas por estas, a partir das pressões vivenciadas, e ao mesmo tempo manter o controle, o que revela a necessidade de enfrentamento de um paradoxo desafiador.

Por fim, o enigma de pessoas relatado por Mintzberg (2010) retrata o "beco da confiança" em que é feita a observação de que para gerir com eficácia, um dos elementos necessários é a confiança entre gerentes e seus funcionários. $\mathrm{O}$ autor menciona que há uma linha tênue entre a confiança e a arrogância nesta relação devido às posições hierárquicas ocupadas e ressalta que o gerente tem como papel zelar para que o mesmo tenha seus funcionários caminhando ao seu lado e atendendo aos propósitos empresariais (MINTZBERG, 2010). 
Apresentados os principais conceitos teóricos que fundamentam o estudo, segue-se a demonstração do percurso metodológico.

\section{$3 \quad$ Metodologia}

Enquanto abordagem, a construção do estudo foi pensada de modo qualitativo. Segundo Chizzotti (2006, p. 28), "o termo qualitativo implica uma partilha densa com pessoas, fatos e locais que constituem objetos de pesquisa, para extrair desse convívio os significados visíveis e latentes que somente são perceptíveis a uma atenção sensível". A ênfase deve estar na interpretação dos significados que os sujeitos atribuem ao fenômeno (CHIZZOTTI, 2006).

A pesquisa possui um caráter exploratório e descritivo. $\mathrm{O}$ primeiro enquadramento leva em conta o número reduzido de trabalhos que sistematizaram o conhecimento que foi sendo acumulado, tomando-se como referência a ausência de trabalhos que dialogaram com os enigmas propostos por Mintzberg (2010) no contexto de micro e pequenas empresas. Já a definição como descritivo leva em conta que será registrado como determinada comunidade vivencia o fenômeno que será observado, especificando práticas cotidianas (VERGARA, 2013). Logo, foram investigadas 45 empresas da cidade de Belo Horizonte - MG, considerando a abordagem feita ao gerente de cada uma delas. Com o intuito de garantir o anonimato, os respondentes foram denominados "E01", "E02" e assim até "E45".

O processo de coleta de dados foi pensado a partir da aplicação de um questionário composto por nove questões abertas que relacionavam os três Enigmas de Pessoas, conforme apêndice. Os participantes receberam o questionário e foram instruídos a responder a partir de suas vivências como gerentes nos respectivos estabelecimentos. Os dados foram categorizados e observados à luz da análise de conteúdo. Esta "refere-se ao estudo de textos e documentos. É uma técnica de análise de comunicações, tanto associada aos significados, quanto aos significantes da mensagem" (VERGARA, 2013, p. 14).

\section{Apresentação e análise dos resultados}

\subsection{Perfil dos entrevistados}

Dentre os 45 entrevistados, 27 são do sexo masculino e 18 são do sexo feminino. A faixa etária dos mesmos variou da seguinte forma: 06 pessoas - 20 a 25 anos; 05 pessoas -26 a 30 anos; 04 pessoas - 31 a 35 anos; 08 pessoas - 36 a 40 anos; 03 pessoas - 41 a 45 anos; 07 pessoas - 45 a 50 anos; 12 pessoas - mais de 50 anos.

Em relação à escolaridade, a maioria dos entrevistados concluiu o Ensino Superior (53,33\%); 24,44\% concluíram o Ensino Médio; 20,00\% possuem o Ensino Superior incompleto; e 2,23\% tiveram seus estudos findados no Ensino Fundamental. Não houve entrevistados que declararam as outras duas categorias: Ensino Fundamental incompleto e Ensino Médio incompleto.

Observa-se que o grupo de pessoas participantes das entrevistas teve, em sua maioria, homens como gerentes de pequenos negócios, caracterizados como adultos, visto que a maioria deles declarou idade superior a 29 anos (idade que permite a classificação de fases: saída da juventude e entrada na vida adulta, segundo o Estatuto da Juventude (BRASIL, 2013). Além disso, a maioria dos entrevistados teve a oportunidade de estudar e formar-se em um curso superior, o que demonstra um público possivelmente com maior acesso à informação. 


\subsection{Desvendando o enigma de pessoas}

Ao que este artigo se propõe, as pessoas dentro de uma organização simbolizam um enigma a ser desvendado diariamente por seus gerentes para uma melhor gestão, englobando políticas e práticas que atendam seus empregados e, assim, garantindo maior produtividade (MINTZBERG, 2010). Na sequência, seguem-se os desdobramentos do "enigma de pessoas".

\subsubsection{O enigma da ordem}

Para investigar este enigma, os entrevistados responderam ao seguinte questionamento: "As organizações precisam de ordem. Às vezes também precisam de desordem, de serem chacoalhadas! Você concorda com essa afirmação? Por quê?". Os retornos obtidos revelaram 16 gerentes que discordam da afirmação. Alguns deles (E04, E22, E44, E45, E25) alegam que as empresas precisam de organização, dedicação e empenho para melhorarem. E28 acredita que regras devem ser seguidas. Neste mesmo sentido, E01, E11 e E41 acreditam que uma empresa organizada e bem planejada não precisa de desordem.

O entrevistado E06 defende que a organização pode ser chacoalhada sem desordem e E33 relata que chacoalhar só funciona para empresas sem objetivo. Outros não entram no mérito de precisão, mas defendem que desordem gera prejuízo (E05, E07, E12, E14, E31, E37). Já E06 defende que a empresa pode ser chacoalhada sem desordem e propõe uma comissão para tal.

Em meio a todas as circunstâncias abordadas pelos entrevistados ao discordarem da afirmação feita pelo entrevistador, pode-se confirmar o que Lorentz et al (2014) verificou em relação aos gerentes quando menciona que não se pode querer determinar como certas ou erradas as ações de uma função gerencial, pois a atuação de um gerente engloba lidar com pessoas e, também, com a sua própria personalidade, gênero, idade, etc.

Dentre aqueles que concordam com a primeira afirmação, há os que acreditam que as situações de instabilidade favorecem a identificação de falhas que precisam ser corrigidas e obrigam as organizações a se rearranjarem para solucioná-las (E03, E16, E19, E20, E24, E35, E39). Alguns alegam que a chacoalhada favorece no processo de inovação e reestruturação das organizações (E08, E10, E13, E17, E18, E23, E27, E30, E36, E38), enquanto outros defendem que a instabilidade auxilia na alteração do clima organizacional (E21).

O gestor E26 menciona que ao envolver trabalho com pessoas não há como ser extremamente rígido; a chacoalhada, portanto, corrobora para maior flexibilidade por parte da gestão. O gestor E40, também, respondeu voltando-se exclusivamente para gestão de pessoas ao afirmar que a desordem é causada pelo remanejamento de cargos. Os gestores de E15, E32, E34 generalizaram ao afirmarem que as regras nem sempre podem ser seguidas ou tudo que foi planejado consegue ser cumprido, assim como, o gestor de E09, complementa que nem todos os setores da organização podem ser chacoalhados, por exemplo, o financeiro. Em contrapartida o gestor de E02 relata que mesmo em uma empresa organizada, o processo de desordem é individual de cada funcionário, o que desencadeia a chacoalhada na organização.

Pode-se perceber que a maioria dos entrevistados concordou com a afirmativa e que, dentre os que concordam a maioria associa o ato de chacoalhar à gestão de pessoas da empresa, à reorganização e à inovação. Estas percepções corroboram aos escritos de Hill (1993) em que a autora menciona os diversos atores organizacionais como responsáveis de sucessos e fracassos nas organizações e que para lidar com isso é necessária uma postura flexível por parte dos gerentes para saber lidar com todas as complexidades do ambiente laboral. 
O segundo questionamento feito aos entrevistados foi: "A organização pode precisar de previsibilidade, mas o mundo tem o péssimo hábito de ser imprevisível de vez em quando. Você concorda com essa afirmação? Por quê?". Os gerentes que discordam, mencionam que uma organização estruturada deve prever todas as possibilidades (E18), mas que mesmo havendo planejamento, os imprevistos obrigam a organização a alterar todas as suas metas (E45), mas ainda assim com previsões estabelecidas. O gestor E05 defende que o país precisa de um equilíbrio produtivo.

Dentre os que concordam com a afirmação declarada, E02, E03, E09, E11, E13, E15, E16, E21, E25, E26, E35 e E41 asseveram que é impossível prever todas as possibilidades. O gestor E04 afirma que as organizações nem sempre estão preparadas para lidar com imprevistos e os gestores E14, E30, E37 e E43 remetem a impossibilidade de previsões ao governo e à economia.

Já os gestores E17, E22, E23, E27, E32 e E37 acreditam que quem gere/administra uma organização deve ser versátil e flexível para saber lidar com mudanças. Os gestores E24, E29, E38 e E39 afirmam que apesar das imprevisibilidades, se o gestor estiver atento a todas vertentes durante o planejamento, não haverá déficit para organização. Os gestores de E36 e E44 alegam que imprevistos obrigam a organização a alterar todos os planos previamente definidos. Houve relatos de que há demandas que surgem com os imprevistos (E01) e que muitas vezes os melhores planos e oportunidades são em consequência dos mesmos (E07 E10 e E12). Complementarmente, alguns gestores (E08, E20 e E33) alegam que há fatores externos que interferem na previsão das organizações.

Verificadas as respostas, a maioria dos entrevistados concorda com a afirmativa e assegura a impossibilidade de plena previsão para as empresas e, segundo a opinião dos próprios gerentes, apesar da imprevisibilidade, estes devem ter destreza para saber lidar com acontecimentos não previstos. Estas compreensões estão de acordo com o que Mintzberg (2010) menciona sobre desordem controlada nas organizações, isto é, o gestor deve usar de artifícios de controle para lidar com situações adversas.

O terceiro questionamento realizado aos entrevistados adotou como sequência, a seguinte afirmação: "O gerente é aquele cujas responsabilidades são suficientemente amplas e cujo trabalho é flexível o suficiente para lidar com as incertezas e ambiguidades. Você concorda com essa afirmação? Por quê?". Nas respostas obtidas referente à discordância da sentença, o gerente E24 menciona que as responsabilidades devem ser compartilhadas e que, assim como dito por E37 e E10, a flexibilidade não deve ser generalizada para todas as situações.

Neste mesmo sentido, o gerente E38 alega que as responsabilidades são amplas e que se deve ter o cuidado para não perder o foco ao ser muito flexível. Já o gerente da E33 alega que a amplitude de atuação do gerente é limitada. Os gestores E31 e E35 e exemplificaram situações vivenciadas como falta de funcionário ou atrasos dos mesmos e, portanto, expressam-se por não haver espaço para a flexibilidade.

Em contrapartida, há os gerentes que concordam com a afirmativa. Nestas respostas, verificaram-se diversas perspectivas, como é o caso de E04 que mencionou que os diretores cobram dos gerentes a antecipação de soluções para possíveis problemas, além de caber a estes serem flexíveis e dominarem todas as áreas da empresa (E06, E07 e E45). Há também quem defenda que o gerente deve ter liberdade de atuação, como citado pelo gerente E11. 
Por conseguinte, os gerentes E20, E23, E27, E34 e E45 afirmam que as responsabilidades do cargo são amplas e que a resolutividade dos problemas exige flexibilidade. E22 e E32 mencionam que o gerente deve resolver todos os problemas da organização. O gestor E21 afirma que os imprevistos devem ser resolvidos da melhor maneira possível. E em todos os casos, observa-se a flexibilidade como alternativa às resoluções dos problemas (HILL, 1993).

Há quem concorde justificando que a afirmativa é a essência do gerente (E02, E08, E12, E14, E15, E16, E36 e E39). Além disso, E30 acrescenta que cabe ao gerente ser mediador de conflitos e E17 afirma que depende do perfil da empresa, ou seja, se a empresa for flexível pode haver discussões prévias para tomada de decisão em conjunto. Outro posicionamento é referente àqueles que concordam parcialmente, como o gerente E28 que acredita não ser possível ser flexível em todas as situações e como o gerente E37 que afirma que algumas situações não podem ser previstas.

Pode-se perceber que a grande maioria dos entrevistados concorda com a afirmativa, mas várias são as justificativas para tal, portanto, de certa forma não há um consenso. Esta percepção vai de encontro ao que Mariano e Moscon (2018) constataram sobre divergências em modos de gerir, isto é, independentemente do modo como um gerente encara as suas responsabilidades, este busca pela melhoria do desempenho dos trabalhadores e, consequentemente, do seu próprio trabalho.

Finalizando os questionamentos sobre o enigma da ordem, indagou-se sobre a seguinte afirmação: "A ordem demais deixa o trabalho rígido e distante, enquanto a ordem de menos impede que as pessoas funcionem. Você concorda com essa afirmação? Por quê?". Alguns dos gerentes que discordam desta afirmação acreditam que o comportamento depende da equipe que a empresa possui e da intensidade de rigidez necessária para que a mesma aja corretamente (E09, E15, E32, E33, E42 e E43). Já o gerente E28 alega que um gestor mais rígido consegue manter a empresa organizada, no entanto, quando flexível, mantém uma maior harmonia dentro da mesma. O gerente E22 cita que a disciplina é necessária, pois em desordem não há produtividade.

Novamente, a maioria dos gerentes concorda com a afirmativa, dentre eles E02, E03, E06, E10, E11, E13, E18, E20, E21, E24, E27, E34, E37, E38, E40, E45 que afirmam a necessidade de haver equilíbrio para que não haja opressão, mas se alcancem os objetivos. O gerente E07 acrescenta que ordem demais culmina em falta de inovação. Neste mesmo sentido, E17 acrescenta que o excesso de regras acarreta perda dentro da burocracia, mas que é necessário ter planejamento e metas. Os gerentes E25 e E44 destacam que a desordem deixa as pessoas perdidas. Já os gerentes E23 e E35 defendem que o excesso de ordem deixa os funcionários tensos e o excesso de liberdade pode ser confundido com pouca responsabilidade. Alguns entrevistados baseiam-se na experiência de trabalho para concordar, como é o caso dos gerentes E12 e E14.

Dentre os que concordam parcialmente, há o gerente E08 que afirma que não necessariamente a ordem de menos impedirá que as pessoas funcionem, como dito pelo gerente E39; segundo ele, isso depende do perfil da empresa. O gerente E29 faz ressalva que, apesar de concordar, algumas situações não podem ser flexibilizadas. O entrevistado E41 explica que discorda da primeira afirmação, justificando que há formas de manter a organização sem que o gerente tenha de ser rígido, mas concorda com a segunda, uma vez que o excesso de liberdade permite que os funcionários ajam como quiserem, prejudicando o desempenho. 
Nesta última afirmativa, percebe-se que as opiniões estão divididas e as justificativas para tais são amplas. De fato, o enigma da ordem revela-se desafiador, ao passo que trazer e manter a ordem no próprio trabalho e no trabalho dos outros é uma das funções destinadas ao gerente (MINTZBERG, 2010).

\subsubsection{O paradoxo do controle}

Para este enigma, foi lançado um primeiro questionamento aos entrevistados: "Todas as organizações tendem a ter gerentes perfeitamente empilhados em hierarquias de autoridade pelas quais passam diretrizes "de cima" com objetivo de impor ordem. Você concorda com essa afirmação? Por quê?’. Dentre os que concordam os gerentes E04, E06, E08, E14, E16, E21, E25, E29, E31, E34, E35, E42 fizeram afirmações sobre a necessidade de a hierarquia existir; o gerente E33 menciona que trabalhar sem hierarquia é utópico; os gerentes E10, E17 e E45 explicam que numa hierarquia o contato com os funcionários facilita na fluência do trabalho e, portanto, auxilia na tomada de decisão. Corroborando a esta ideia, os gerentes E40 e E41 alegam que a hierarquia é uma maneira de distribuir e delegar funções. Já gerente E22 se posiciona, afirmando que os funcionários da linha de frente, geralmente, não possuem capacidade para atuar em cargos mais elevados e por isso, deve-se estabelecer uma hierarquia.

O responsável pela E39 discorda da afirmação feita no questionamento da entrevista e revela que, atualmente, os modelos de gerenciamento estão alterados quanto à rigidez na hierarquia. Os gerentes E20 e E23 complementam que nas organizações houve uma redução da hierarquia, o que facilitou a comunicação, melhorou o tempo-resposta e humanizou o trabalho. Neste mesmo sentido, os gerentes E07, E36 explicam que nem todas as empresas possuem estrutura hierarquizada. Já o gerente E38 alega que apesar dos líderes serem os responsáveis pela elaboração de diretrizes e metas, a distância entre liderança e linha de frente deve ser reduzida. Ainda dentre os que discordam, o gerente E37 afirma que o objetivo da hierarquia não é impor ordem e sim, coordenar melhor as atividades dos empregados. Tem-se ainda o gerente E11 que embasa sua discordância, afirmando que gerência rígida e engessada não é efetiva. O gerente da E24 que alega que os objetivos podem ser cumpridos sem imposição, mas depende do perfil do líder. Já o gerente da E02 afirma que a hierarquia precisa de flexibilidade para que a gestão flua.

O segundo questionamento sobre este paradoxo, perguntou: "Metas podem ser arbitrárias, até mesmo contraditórias, decididas do nada a partir de listas de desejos, sem considerar as situações difíceis em que precisam ser atingidas. Você concorda com essa afirmação? Por quê?". As respostas que concordam com esta afirmação, iniciam com a afirmação do gerente E19 que alega que o foco deve ser primordial e assim como E10 e E13 concordam que quando as metas não condizem com a realidade da organização, os funcionários ficam estressados por serem, muitas vezes, inalcançáveis. O gerente E08 assume que as metas da sua empresa são arbitrárias e muitas vezes propositalmente inalcançáveis. O gestor E34 defende que as metas exijam que os funcionários trabalhem, muitas vezes, sem respeito com os colegas, portanto, são prejudiciais aos mesmos e causam estresse. Já o gestor E31, apesar de concordar, defende que há imprevistos que afetam as metas. Enquanto o gestor da E04 explica que as metas são determinadas por pessoas em cargos elevados que ignoram a realidade da empresa. Já o gestor E38 concordou utilizando como base a justificativa de que é necessário planejamento estratégico. 
Os gestores da E02, E06, E09, E16, E20, E21, E22, E23, E24, E35, E36, E40, E45 discordam, pois acreditam que antes de estabelecer metas, há um planejamento estratégico para que as mesmas não sejam arbitrárias. Da mesma forma, os gestores E17 e E43 alegam que as metas devam ser discutidas com todos os envolvidos antes de serem definidas. O gerente E15 discorda e justifica que em situações de dificuldade pode-se discutir até mesmo a retirada das metas. Concordando com as demais respostas, o gestor E03 assume que se as metas forem definidas da maneira citada na afirmativa, é preferível não tê-las. Os gerentes E32 e da E33 defendem que as metas devam ser definidas considerando todo o contexto do ambiente externo. Semelhante a isso, os gerentes E30, E41 e E44 acreditam que as metas tem que ser alcançáveis, caso contrário, desmotivam os funcionários. O gestor da empresa E25 explica que as metas devem ser feitas a partir do perfil dos funcionários para que não sejam inúteis ou desmotivadoras. Por fim, o gestor E29 discorda utilizando como base a sua vivência, na qual todas as metas são alcançáveis.

Assim, verificou-se que a maioria dos entrevistados discordou da afirmativa com a justificativa de que é necessário planejamento estratégico e participação de todos os envolvidos na definição das metas para que estas, de fato, sejam consideradas propostas a serem seguidas.

Em se tratando do controle que pode ser paradoxal, conforme mencionado por Mintzberg (2010), o terceiro questionamento aos gestores foi lançado: "Às vezes é possível ignorar a cadeia de comando, pelo menos quando se tem a sabedoria de saber onde e como desobedecer a ordens. Você concorda com essa afirmação? Por quê?". Os gerentes E02, E10, E34, E43 e E45 concordam com a afirmativa utilizando a justificativa de que se for para o bem da empresa é licito, bem como E20 e E39 alegam que as normas podem dificultar a agilidade dos processos na organização. Neste mesmo contexto, o gestor E40 certifica que essa atitude demonstra iniciativa e autonomia por parte do funcionário. Os gestores E04 e E05 concordam com a justificativa desde que o resultado seja aumento da produtividade. O gerente E37 defende que em alguns casos é possível ignorar a cadeia de comando. Do mesmo modo, E15, E31 e E36 explicam que concordam com a afirmativa, pois os subordinados podem fazer propostas aos seus gerentes. Ainda concordando com o questionamento da entrevista, E11, E13 e E14 explicitam que é benéfico para o gerente, entender mais intimamente o processo da empresa que está gerenciando. Se o funcionário tiver muito conhecimento sobre a empresa é justificável, informaram que os gestores E03, E06, E17, E25 e E33. O gestor E30 defende o que chamou de "desobediência sábia".

O gestor E38 discorda da afirmativa justificando que em uma gestão democrática e descentralizada as decisões são tomadas coletivamente, portanto, descumprir ordens não condiz com a realidade. Nesta mesma linha de raciocínio, E22 e E44 explicam que cada funcionário deve cumprir suas funções e possuem suas responsabilidades. Já os gestores E01 e E22 alegam que as ordens devem ser cumpridas estando certas ou não para que haja manutenção da organização da empresa. O gestor E07 discorda, no entanto, abre exceção para o que chama de “casos negociáveis". O gestor E28 discorda baseado na sua vivência de que ignorar a cadeia de comando não é o melhor caminho.

Ao que se refere ao Paradoxo da Ordem como um enigma da Gestão de pessoas, tem-se que para trabalhar numa "desordem controlada" (MINTZBERG, 2010) deve-se ter atenção à rigidez hierárquica, às metas estabelecidas para as organizações, bem como compreender mais sobre autonomia, seja para a atuação de gerentes, seja para a atuação de funcionários. Num 
olhar gerencial, as tarefas de um gerente atingem um nível de complexidade considerável, ao passo que precisa lidar com fatores externos e internos das organizações, intrínsecos e extrínsecos aos funcionários e a si mesmos.

\subsubsection{O beco sem saída da confiança}

Como ponto relevante do Enigma de Pessoas, aprofunda-se, também, no que tange a confiança (MINTZBERG, 2010). Com base neste contexto, foi elaborado o seguinte questionamento: "Quem gosta de evitar problemas, passá-los adiante ou simplesmente proteger só a si mesmo pode piorar muito a situação para todo mundo. Você concorda com essa afirmação? Por quê?". Dentre os gerentes que concordam com esta afirmação E19 considera que, enquanto equipe, deveria pensar-se coletivamente. E01, E02, E04, E06, E11, E21, E23, E28, E34, E35, E37 acreditam que os problemas devem ser solucionados quando detectados, sem postergação ou proteção individual. Os gerentes E18, E30 e E32 explicam que a responsabilidade pelo problema não deve ser ignorada. E07, E09, E17, E31, E38 acrescentam que aqueles que não se responsabilizam pelos problemas e não pensam na coletividade são prejudiciais para a organização. Do mesmo modo, o gestor E16 alega que ao ignorar os problemas, o funcionário prejudica a empresa.

A falta de autonomia para tentar resolver o problema gera o adiamento da resolução, podendo causar problema maior posteriormente, afirmam os gestores E13 e E45. Simultaneamente, os gestores E10 e E15 afirmam que quando identificado o problema, o funcionário deve tentar solucioná-lo e, se necessário, pedir ajuda para que não seja gerado um problema em cadeia. Os gestores E25, E36, E40 acreditam que os problemas podem ser resolvidos em conjunto, com comprometimento de todos. Outrossim, passar o problema adiante pode apenas adiá-lo, afirma o gerente E24. Os gestores E12, E20, E22, E33, E41 acreditam que a não resolução dos problemas quando detectados podem acarretar situações ainda piores. Portanto, os problemas devem ser enfrentados, conforme mencionado pelos gerentes E42, E43, da E44.

Contrariamente aos demais gerentes, E03 discorda da afirmativa e alega que quanto mais rápido o problema for solucionado, mais simples ele será, independentemente da forma como este será resolvido.

Nas entrevistas também se associou a segurança à confiança quando questionados com a seguinte pergunta: "Os gerentes, quando ficam sozinhos, precisam passar a impressão de que sabem o que estão fazendo, mesmo quando não tem certeza, para que os outros se sintam seguros para segui-los. Você concorda com essa afirmação? Por quê?". Grande parte dos gerentes (E01, E06, E07, E08, E10, E18, E21, E22, E25, E26, E29, E34, E39, E41, E45) concorda com a assertiva e alega que o gerente é responsável por passar segurança e confiança para os subordinados para que a empresa mantenha-se organizada e o líder tenha credibilidade. Os gerentes E04 e E16 complementam que ao promover confiança, a produtividade é aumentada, pois o líder deve representar um modelo a ser seguido. Neste mesmo sentido, E12 explica que o gestor nunca deve demonstrar fraqueza. Os gerentes E28 e E37 anuem que o gerente tem a função de liderança e, portanto, deve ser um exemplo para os funcionários. O gestor E31 argumenta que o gerente deve ser seguro e direto e o gerente E34 justifica que o cargo exige postura.

Já os gerentes E02, E32, E33 afirmam que embora o gestor deva ter conhecimento para assumir o cargo, não é demérito pedir ajuda. Dentre os que discordam, estão os gerentes E13, 
E23, E38 e E40 que preferem assumir seus limites de conhecimento e pedir ajuda. O gerente E43 destaca que, pela sua vivência, trabalha em equipe. Complementarmente, o gerente E42 relata que não há motivos para demonstrar segurança aos demais. E20 justifica que discorda porque o líder deve ser reconhecido pelo seu conhecimento e não pelo cargo que ocupa. $\mathrm{O}$ gerente E17 justifica que um líder deve ser reconhecido pela honestidade, integridade e idoneidade, nada mais que isso. Os gestores E09, E11, E24, E36 explicam que quando se tem um bom relacionamento com a equipe pode-se pedir ajuda sem hesitação. O gestor E15 ainda complementa as respostas mencionando que ao compartilhar com a equipe, os mesmos se sentirão parte do processo decisório e isso é positivo para o envolvimento dentro da organização. Os gestores E19 e E30 defendem ainda que o gestor que comete essa atitude de ter que ser o exemplo, se distancia da equipe.

O terceiro questionamento buscou relacionar confiança versus arrogância por parte dos gerentes, pelo fato de ocuparem cargos de liderança, sendo assim eles foram questionados: "Não é preciso muito esforço para que alguém com o emprego de gerente pare de ouvir, se isole e pense em si mesmo como heroico A linha entre a confiança e a arrogância é fina. Você concorda com essa afirmação? Por quê?". Dentre os que concordam estão os gerentes E03, E06, E21 e E40 afirmando que as pessoas se sentem tão seguras que acreditam que conseguiram as conquistas sozinhas, esquecendo-se da estrutura de retaguarda. Os gerentes E17, E20 e E23 relatam que o período de gerência de pessoas com essa atitude será curto, pois ninguém consegue trabalhar sozinho. Os gerentes E07, E08, E11, E12, E19, E25, E37 e E41 concordam que é inerente ao ser humano inflar o ego quando em posição de poder. Os gerentes E02 e E24 relatam que como o cargo envolve poder é comum acontecer essa atitude, no entanto, explicam que o gerente deve pensar que está no cargo e não que é o dono do cargo.

O gestor E09 exemplifica que a arrogância pode impedir que a ideia de um subordinado seja aproveitada. Neste sentido, segundo o gestor E34, a arrogância contribui para a perda da confiança por parte dos funcionários. $\mathrm{O}$ gestor E28 relata que muitos gerentes só pensam em si próprios e não medem esforços para alcançar suas metas. $\mathrm{O}$ gestor E36 relata que a gestão compartilhada está cada vez mais em voga. Os gerentes E30 e E31 concordam com o questionamento, mas explica que os gerentes atuais estão mais próximos das suas equipes. $\mathrm{O}$ gerente E42 relata que muitas pessoas não sabem liderar por isso tornam a afirmação verdadeira. O gerente da empresa E33 justifica que é preciso ser humilde para aceitar correções e que a prepotência é natural do ser humano. Os gerentes E04 e E22 destacam que os gerentes arrogantes se consideram detentores de todo conhecimento e, portanto, não aceitam opinião.

Dentre os que discordam há o gerente E16 que alega uma relação de arrogância com a personalidade de cada indivíduo e não do cargo que exerce. Já o gestor E35 justifica que essa atitude é fruto de estresse. Enquanto os gestores E32 e E45 afirmam que o gerente não pode ser arrogante porque não é possível trabalhar sozinho. Os gestores E01 e E43 defendem que o gestor deve saber ouvir, mas se necessário, ele deve isolar-se para tomar decisões que não agradam a todos.

Considerando os três questionamentos direcionados à relação de confiança entre gestores e funcionários, observa-se que os gerentes tendem a priorizar a coletividade como forma de manter um vínculo afetivo e efetivo com seus funcionários para atingir bons resultados organizacionais. A maior parte deles percebe que proteger-se de um problema sem pensar num todo, não é a melhor solução. Outro ponto levantado aponta que o líder deve ser um exemplo 
para seus funcionários, mas também é essencial que o mesmo demonstre que a sua liderança não é composta apenas pelo cargo hierárquico maior, mas sim por um grupo que contribui para o todo. Isso é verificado como um desafio contra a arrogância que um cargo de liderança pode favorecer e possivelmente descontrolar toda uma equipe.

A partir das colocações dos gerentes e do roteiro de entrevista semiestruturado foi perguntado aos gerentes sobre o que eles complementariam ao tema de Enigma de Pessoas nas organizações em que atuam, a partir de suas vivências: "Para você, quais os principais enigmas relativos à gestão de pessoas na organização em que atua? Como a organização está lidando com tais questões?". Diversos apontamentos foram verificados. O gestor E44 relata que o pessoal está mal capacitado e que houve promoções erradas, mas não explicou com detalhes a situação vivenciada. Já o gestor E22 relata a dificuldade em encontrar um funcionário que queira trabalhar, de fato. Para o gestor E04, os enigmas estão sendo o de manter firmeza sem autoritarismo para tal e de realizar reuniões de curta duração para integrar a equipe.

O gestor de E31 destaca estar vivenciando a falta de compromisso e assiduidade dos funcionários e que tem aplicado advertências nos casos extremos. O gestor E14 relata estar enfrentando a incompetência dos funcionários e que está tentando corrigir a situação com tutela. Os desafios enfrentados pelo gestor E12 estão relacionados à interiorização por parte dos funcionários sobre a proposta da empresa. Para isso, ele tem utilizado a amizade e a cumplicidade como "ferramentas" para solucionar o problema. Os gestores E07 e E36 relatam a busca por conhecer as diferenças entre culturas e pessoas para que as ações motivacionais sejam direcionadas.

O gestor E33 destaca enfrentar a falta de compromisso dos funcionários e que está utilizando como estratégia a troca de pessoal. O gestor E38 relata a dificuldade em conseguir profissionais aptos, portanto, a empresa tem buscado profissionais de outras áreas para a atuação no negócio (lecionar). Os gestores E40, E43 e E45 explicam que trabalhar com o ser humano é difícil, pois não são todas as atitudes que agradam. Os gestores E28 e E39 relatam que a principal dificuldade é motivar seus funcionários. Os gestores E02, E15, E20 e E24 aprofundam mais ao afirmar que a dificuldade está em encontrar o ponto ótimo para agradar clientes e funcionários, para tal, treinamentos estão sendo oferecidos.

O gestor E41 possui funcionários com dificuldade de execução das ações, portanto, também, está investindo em capacitação. Para o gestor E21 a dificuldade está em encontrar um funcionário polivalente e proativo; por este motivo, estão procurando dentro da própria empresa os funcionários que possuem esse perfil para promovê-los. O gestor E30 destaca que a dificuldade é de fazer com que os funcionários se envolvam com os ideais de empresa. Já o gestor da E32 relata dificuldades com erros profissionais quanto à higiene e à educação e está tentando corrigir com conversas, educação e advertências.

O gestor E03 aponta ter como enigma o conhecimento geral sobre a empresa e que tem buscado conhecer toda a organização. O gestor da empresa E35 relata estar tendo dificuldades com a falta de responsabilidades dos funcionários e dos fornecedores. Já o gestor E09 destaca a dificuldade em separar o pessoal do profissional uma vez que trabalha em empresa familiar.

Observa-se que cada gerente demonstrou suas particularidades quanto ao que eles têm enfrentado como gestor das organizações em que atuam. Observa-se também que muitos dos desafios estão tendo como tentativas de soluções uma maior interação na relação gerentefuncionário para atingir resultados proveitosos para ambos os lados e para a empresa como um 
todo. Estes desafios corroboram a Mariano e Moscon (2018) que evidenciam como os direcionamentos de um gestor podem afetar a forma de comportamento dos funcionários frente aos desígnios organizacionais.

Vale ressaltar ainda que alguns gerentes mencionaram buscar por motivações para seus funcionários, entretanto, em teorias motivacionais, verifica-se que não é possível motivar o outro, porque a motivação é intrínseca ao indivíduo, tendo, portanto, como alternativa de solução, aproveitar o potencial motivacional já existente em cada um (BERGAMINI, 2003) e assim pensar em propostas para atingir a motivação de um funcionário. A partir dos resultados encontrados neste estudo qualitativo, seguem-se as considerações finais.

\section{$5 \quad$ Considerações finais}

O presente artigo teve como objetivo geral compreender como gerentes de pequenos negócios lidam com dilemas relacionados à Gestão de Pessoas na cidade de Belo Horizonte, a partir dos inescapáveis enigmas de gestão, discutidos por Mintzberg (2010), em especial, os "enigmas de pessoas". Para tal, foi realizada uma pesquisa de cunho qualitativo, exploratório e descritivo, apoiada na aplicação de um questionário aberto a 45 gestores de empresas de pequeno porte, que atuam no município de Belo Horizonte, com consequente categorização e análise baseada na análise de conteúdo.

Observou-se a partir da análise das respostas relacionadas ao "enigma da ordem", que 16 gerentes alegam que as empresas precisam de organização, dedicação e empenho para melhorarem, sendo que vários dos entrevistados não entraram no mérito da necessidade de "chacoalhada", mas acreditam que a desordem gera prejuízo e precisa ser apurada. Enquanto outros 10 defendem que a "chacoalhada", reforçando o termo utilizado pelos sujeitos, favorece o processo de inovação e reestruturação das organizações.

Ao discutir sobre previsibilidade, 12 gerentes asseveram que é impossível prever todas as possibilidades, mas a grande maioria dos entrevistados assegura que apesar da imprevisibilidade, é possível ter destreza para lidar com as situações não previstas, a partir do conhecimento prévio adquirido na gestão da organização. Ao serem entrevistados sobre as responsabilidades do gerente, várias foram as justificativas, no entanto, há um consenso sobre a grande responsabilidade dos gerentes e a flexibilização para lidar com incertezas e ambiguidades. Ainda sobre o enigma da ordem, discutiu-se sobre a rigidez no trabalho e 16 gerentes destacaram a necessidade do equilíbrio para que os objetivos fossem alcançados e não houvesse opressão.

Ao analisar as respostas sobre o "paradoxo do controle", 12 gerentes defendem a necessidade de hierarquia e 13 acreditam que as metas para a organização devam ser planejadas para que não haja arbitrariedade. Houve destaque para a discussão sobre cadeia de comando, uma vez que não foi possível observar um consenso entre os entrevistados, ao considerar que uns defendem a possibilidade de ignorar a cadeia de comando em algumas situações e outros a defendem como primordial.

$\mathrm{Na}$ análise "sobre o beco sem saída da confiança", a grande maioria defende que o fato de passar problemas adiante acarreta piora da situação, sendo que 11 dos entrevistados asseguram que os problemas devam ser resolvidos quando detectados. No quesito conhecimento do gerente, 15 líderes concordaram que o gerente é responsável por transmitir segurança e confiança para os subordinados, portanto, consideram válido fingir uma certeza 
para ter credibilidade com a equipe. Percebeu-se a manutenção da coletividade para estreitamento de vínculos e reconhecimento de hierarquia.

Entende-se que o trabalho possui limitações referentes à generalização dos gestores de pequenos negócios, isto é, falta de especificidade de segmentos onde atuam em seus negócios, para melhor compreensão da realidade observada. Desta forma, sugere-se como agenda de pesquisa ampliar a investigação em termos de sujeitos e quantidade de questões, sendo possível direcionar a pesquisa para segmentos específicos e, por consequência, traçar comparativos.

Conquanto, o estudo corrobora corporativamente/socialmente por discutir assuntos contemporâneos referentes às organizações, pertinentes a gestores, uma vez que o ato de gerir pessoas apresenta dilemas enfrentados pela maioria das empresas, tornando-se relevante o compartilhamento de vivências; e academicamente, por explorar estudos da Administração de autores renomados como Mintzberg, possibilitando prosseguir com novas ponderações e descobertas a partir de novas realidades estudadas. Assim, a medida que estudos em gestão de pessoas reverberam, legitima-se o tema como fator estratégico dentro das empresas sendo, portanto, passível de estudos dentro da Administração.

\section{REFERÊNCIAS}

BASTOS, A. V, B.; et al. Comprometimento no Trabalho: fundamentos para a gestão de pessoas. In: BORGES, L. de O.; MOURÃO, L. (Org.). O trabalho e as organizações: atuações a partir da Psicologia. Porto Alegre: Artmed, 2013. p. 280-310.

BASTOS, A. V. B; LIRA, S. B. Comprometimento no trabalho: um estudo de caso em uma instituição de serviços na área de saúde. Organizações \& Sociedade, v. 4, n. 9, p. 39-64, maio/ago,1997.

BAUMAN, Z. Tempos Líquidos. Rio de Janeiro: Jorge Zahar Ed., 2007.

BERGAMINI, C. W. Motivação: uma viagem ao centro do conceito. GV-executivo, v. 1, n. 2, p. 63-67, 2003.

BRANDSTÄTTER, H. Personality aspects of entrepreneurship: A look at five metaanalyses. Personality and individual diferences, v. 51, n.3, p. 222 - 230, 2011.

CHIZZOTTI, Antônio. Pesquisa qualitativa em ciências humanas e sociais. Petrópolis: Vozes, 2006.

DRUCKER, P. Inovação e espírito empreendedor (Entrepreneurship). Práticas e princípios. São Paulo: Cengage Learning, 2008.

DRUCKER, P. O Gerente Eficaz. Rio de Janeiro: LTC, 1967.

DUTRA, M. R. S. et al. Comprometimento Organizacional: um estudo comparativo entre gerentes e não gerentes do setor público mineiro. In: VII Encontro de Administração Pública e Governança da ANPAD, 2016. Anais... São Paulo: ANPAD, 2016.

FAYOL, H. Administração Industrial e Geral. São Paulo: Atlas, 1990.

GEM, Global Entrepreneurship Monitor. Empreendedorismo no Brasil - Relatório Executivo, 2017.

Disponível

em:

https://m.sebrae.com.br/Sebrae/Portal\%20Sebrae/Anexos/Relat\%C3\%B3rio\%20Executivo\%2 0BRASIL_web.pdf. Acesso em: 22 de julho de 2018. 
GRUM, R. Desemprego Gerencial e Mudança nos Sistemas Simbólicos Imperantes nas Classes Médias Brasileiras. In: EnANPOCS, 19, 1995, Caxambu. Anais... Caxambu: ANPOCS, 1995. HILL, L. A. Novos Gerentes. São Paulo: Makron Books, 1993.

LIKERT, R. Novos Padrões de Administração. São Paulo: Livraria Pioneira Editora, 1971.

LORENTZ, C. N.; LIMA, L. C.; DIAS, B. O. S. V.; GUIMARÃES, L. V. M. Subjetividade e identidade dos gerentes frente aos novos papéis exigidos no atual contexto organizacional. Revista Gestão \& Tecnologia, v. 14, n. 3, p. 219-243, 2014.

MARCHESAN, R.. Férias, horário e almoço: entenda 12 pontos da reforma trabalhista. UOL, São Paulo, 11 jun. 2017, Economia. Disponível em: https://economia.uol.com.br/noticias/redacao/2017/07/11/ferias-horario-e-almoco-entenda-12pontos-da-reforma-trabalhista.htm. Acesso em: 20 dez. 2017.

MARIANO, T. L. A. B.; MOSCON, D. C. B. As relações entre as práticas de gestão de pessoas e o desenvolvimento de vínculos com a organização: Um estudo em uma empresa de contabilidade. Gestão \& Planejamento - G\&P, v. 10, 2018.

McCLELLAND, D. C. O poder é o grande motivador. São Paulo: Nova Cultural, 1987.

MESQUITA, J. M. A.; MARQUE, E. V. O Comportamento Empreendedor dos Proprietários/Gerentes das Micro e Pequenas Empresas do setor de beneficiamento de frutos e laticínios na região do Baixo Jaguaribe - CE. In: XLI Encontro da ANPAD, 2017. Anais... São Paulo: ANPAD, 2017.

MINTZBERG, H. Managing: desvendando o dia a dia da gestão. Tradução de Francisco Araújo da Costa. Revisão Técnica: Roberto Fachin. 2010.

MINTZBERG, H. Trabalho do Executivo: o folclore e o fato. Coleção Harvard de Administração, v. 3, p.5-37. São Paulo: Nova Cultural, 1986.

MOTTA, P. R. Gestão Contemporânea. Rio de Janeiro: Record, 1991.

PAIVA, K. C. M. et al. Tempo e gerência: um estudo com gestores do varejo. In: XXXIV Encontro da ANPAD, 2010. Anais... Rio de Janeiro: ANPAD, 2010.

REIJONEN, H. Understanding the small business owner: what they really aim at and how this relates to firm performance. Management Research News, v. 31, n. 8 p. 616-629, 2008.

SEBRAE - Serviço Brasileiro de Apoio às Micro e Pequenas Empresas, 2018. Disponível em: http://www.sebrae.com.br/sites/PortalSebrae/ufs/sp/sebraeaz/pequenos-negocios-emnumeros, 12e8794363447510VgnVCM1000004c00210aRCRD. Acesso em julho de 2018.

SILVA, D. H. L.; PAULO, E. A influência da crise econômica no nível de gerenciamento de resultados: evidências no mercado brasileiro. In: XLI Encontro da ANPAD, 2017. Anais... São Paulo: ANPAD, 2017.

SIMON, H. A. Comportamento Administrativo. Rio de Janeiro: FGV, 1965.

TAYLOR, F. W. Princípios de Administração Científica. São Paulo: Atlas, 1970.

VERGARA, Sylvia Constant. Projetos e relatórios de pesquisa em administração. 14. ed. São Paulo: Atlas, 2013.

WEBER, M. Ensaios de Sociologia. Rio de Janeiro: Zahar, 1946. 